Research Article

\title{
Knowledge and adherence to antiretroviral therapy among adult people living with HIV/AIDS at Tikur Anbessa Specialized Hospital, Ethiopia
}

\author{
Ruth Demessie ${ }^{1}$, Alemayehu Mekonnen ${ }^{2}$, Wondwossen Amogne ${ }^{3}$, Workineh Shibeshi ${ }^{\text {* }}$
}

\begin{abstract}
${ }^{1}$ Department of Pharmacology and Clinical Pharmacy, School of Pharmacy, Addis Ababa University, P. O. Box 1176, Addis Ababa, Ethiopia ${ }^{2}$ School of Public Health, Addis Ababa University, P. O. Box 1176, Addis Ababa, Ethiopia

${ }^{3}$ Department of Internal Medicine, School of Medicine, Addis Ababa University, P. O. Box 1176 Addis Ababa, Ethiopia

Received: 07 February 2014 Accepted: 28 February 2014

\section{*Correspondence to: Workineh Shibeshi, Email: shibeshiworkineh@ gmail.com}

\section{(C) 2014 Demessie $\mathrm{R}$ et al.} This is an open-access article distributed under the terms of the Creative Commons Attribution Non-Commercial License, which permits unrestricted non-commercial use, distribution, and reproduction in any medium, provided the original work is properly cited.

\begin{abstract}
Background: Adherence to antiretroviral therapy (ART) is necessary to achieve best virological response, lower the risk of drug resistance, and reduce morbidity and mortality. The objectives of the current study were to assess the extent of knowledge of patients on treatment plan and regimen, determine the rate of adherence and identify factors related to non-adherence to ART.

Methods: A cross-sectional study was conducted at Tikur Anbessa Specialized Teaching Hospital, Addis Ababa, Ethiopia, using data from both semi-structured interview (self-report) and ART database (pharmacy refill) during the months of March and April 2013 using a total 350 participants.

Results: The results indicated that $33 \%$ of the participants had good knowledge on the treatment plan and regimen. Using self-report and pharmacy refill record, $79.1 \%$ and $72.9 \%$ respectively showed adherence rate of $\geq 95 \%$. Younger people were found to be less likely to adhere to ART (AOR $[95 \%]=0.51[0.30,0.85])$ using pharmacy refill record. Risk factors for ART non-adherence using self-report were use of memory aids $(\mathrm{AOR}[95 \%]=3.46[1.72,6.98])$, treatment satisfaction $(\mathrm{AOR}[95 \%]=2.33[1.22,4.07])$, taking co-medication $(\mathrm{AOR}[95 \%]=0.56[0.32,0.98])$, and regimen switch $(\mathrm{AOR}[95 \%]=0.41[0.19,0.85])$. Whereas using pharmacy refill record risk factors were, knowledge on treatment plan and regimen $(\mathrm{AOR}[95 \%]=2.50[1.39,4.51])$, use of memory aids $(\mathrm{AOR}[95 \%]=2.71[1.34,5.47])$, treatment satisfaction $(\mathrm{AOR}[95 \%]=3.78[1.47,9.71])$, and regimen switch $(\mathrm{AOR}[95 \%]=0.50[0.27,0.92])$.

Conclusion: Older age, good knowledge on treatment plan and regimen, use of memory aids, treatment satisfaction, and not having co-medications and regimen switch showed more adherence to ART.
\end{abstract}

Keywords: Adherence, Non-adherence, Antiretroviral drugs, Antiretroviral therapy, HIV/AIDS

\section{INTRODUCTION}

The human immunodeficiency virus (HIV) continues to be the most important public health crises in the world spreading with a high rate worldwide. ${ }^{1}$ Globally, there were approximately 34 million people living with HIV at the end of 2011, with around two million deaths and three million new infections occurring annually. ${ }^{2}$ Following the introduction of antiretroviral (ARV) drugs; global, national, and regional health initiatives have responded to the HIV/ AIDS pandemic by introducing antiretroviral therapy (ART).
From 2003 to 2010, ARV use in low- and middle-income countries has increased by 22 -fold. ${ }^{3}$ In these countries, an estimated 15 million people needed ART for their own health based on World Health Organization 2010 treatment guidelines and 8 million people living were accessing ART at the end of 2011 up from 6.6 million in 2010 representing an increase of about $20 \%$ and the total treatment coverage of $54 \%{ }^{2,4}$

The Government of Ethiopia introduced the ART program in July 2003 through 12 government hospitals on a co-payment 
basis. In January 2005, free ART through the Global Fund, World Bank and US President's Emergency Plan for AIDS Relief became available in 22 hospitals. ${ }^{5}$ The effectiveness of ART can be limited by several factors such as lack of access to therapy, non-adherence, intolerance, or ARV resistance. ${ }^{6}$ The ARV medication treatment non-adherence is one of the factors that limit effective use of ART. ${ }^{1,7}$ Treatment adherence can be defined using several definitions but in general terms; it is defined as the extent to which a patient's health-related behaviors correspond with medical advice. Non-adherence to ART has been noted as one of the greatest public health challenges associated with the management of HIV/AIDS. A decrease of $10 \%$ in adherence by an individual has been associated with increased HIV ribonucleic acid rate of replication. ${ }^{8}$

In order to slow down the disease progression, achieve an undetectable viral load, and prevent the development of drug resistance, a patient on ARV drugs needs to take at least $95 \%$ of the prescribed doses on time. A $95 \%$ cut-off to define adherence is commonly used by most studies where adherence rate of $\geq 95 \%$ are considered to be adherent while patients with adherence rate of less than $95 \%$ are considered to be non-adherent. ${ }^{8,9}$ The ability to measure ART treatment adherence accurately is critical to identify adherence problems and improve adherence practices. ${ }^{10}$ There is no gold standard to measure adherence and the best method to assess adherence remains unclear. ${ }^{9,11}$ However, the commonly used methods include patient self-report, pill counts, pharmacy refill records, electronic drug monitoring, CD4 count, and physician assessment, the most commonly used method in resource-limited settings being self-report and pharmacy refill records. ${ }^{1,12}$ Self-report is quick and inexpensive method and has been shown to predict clinical outcome with significant association with viral load. ${ }^{11,13}$ The objectives of the current study were to assess the extent of knowledge of patients on treatment plan and regimen, determine the rate of adherence and identify factors related to non-adherence to ART at Tikur Anbessa Specialized Hospital (TASH).

\section{METHODS}

\section{Study setting and design}

The study was conducted in Addis Ababa, Ethiopia at TASH which is tertiary care teaching hospital of Addis Ababa University. The hospital has more than 1700 medical and non-medical staff and offers inpatient, outpatient and emergency services in about 20 specialist clinics and units. Several services are offered in the hospital including Internal Medicine, Emergency Medicine, Surgery, Gynecology and Obstetrics, Pediatrics, Oncology/Chemo-radiotherapy, Radiology, Psychiatry and Dermatology and the pharmacy services. The study was a hospital-based descriptive cross-sectional study and used primary and secondary data collected from patients and from pharmacy database extraction from existing record respectively.

\section{Source and study population}

The source population constitutes of all adult HIV/AIDS patients in all the government hospitals in Addis Ababa. The study population includes adult HIV/AIDS patients on ART in TASH who fulfill all the inclusion criteria.

\section{Inclusion and exclusion criteria}

To be enrolled in the study, participants have to meet the inclusion criteria: Adult HIV/AIDS patients 18 years old and above, outpatients receiving ARVs for at least 3 months at the beginning of the study period and receiving ARVs solely from TASH ART pharmacy.

\section{Sampling and sample size determination}

Eligible HIV-infected adult patients were interviewed when they came to the ART pharmacy to receive their monthly supply of ARVs. Accordingly, the sample size for this study $(\mathrm{N}=350)$ constituted all patients visiting the ART pharmacy and willing to participate in the study period during the month from March to April, 2013 according to the inclusion criteria.

\section{Data collection and analysis}

The principal investigator and other trained data collectors were responsible for conducting the semi-structured questionnaire. The questionnaire consisted of open and closed ended questions consisting the background characteristics of the study participants, questions on knowledge of the treatment plan and regimen. The trained data collectors interviewed HIV/AIDS patients on ARVs as they exit from the facility following their pharmacy visits. Following the interview, for each participants identified by their patient ID number, the ART patient database was used to determine adherence rate over the past one month prior to the study by using pharmacy refill record method and also used to cross check some information of the background characteristics reported by the participants.

Statistical Package for the Social Science (SPSS version 16.0) was used for data entry and analysis. Patients were considered adherent when they have adherence rate $\geq 95 \%$ of the prescribed drugs in a one month recall prior to the study otherwise they were categorized as non-adherent. ${ }^{14,15}$ Knowledge on the treatment plan and regimen was measured by asking five basic questions. The five knowledge questions were then graded out of 5 , where a score $\geq 3$ was classified as good knowledge while a score of $\leq 2$ was classified as poor knowledge and then participants with good and poor knowledge were analyzed against adherence rate. Measure of agreement (kappa) was estimated to evaluate the correlations among the two adherence rate measures used; self-report and pharmacy refill record. 


\section{Ethical clearance}

Ethical clearance was obtained from the Ethics review Board of School of Pharmacy and Department of Internal Medicine, School of Medicine, Addis Ababa University. Data collection was conducted after obtaining written consent from participants with their right not to answer any of the questions and terminate the questionnaire if they are not comfortable. Confidentiality was maintained throughout the study using data collectors who are not part of TASH health care team, by avoiding personal identifiers such as names of patients and limiting the access of data to unauthorized people.

\section{RESULTS}

\section{Background characteristics}

A total 350 patients have participated in the study making a response rate of $87 \%$. One hundred and fourteen $(32.6 \%)$ and $236(67.4 \%)$ were males and females, respectively. Mean age was $39.8 \pm 10.3$ years; median age was at 40 years with minimum and maximum ages of 19 and 70 years, respectively. The majority of the respondents $(51.1 \%)$ had completed secondary level of education, $19.4 \%$ had finished tertiary education, $18.4 \%$ had primary education, and $11.1 \%$ had no education (Table 1).

\section{Knowledge on the treatment plan and regimen of the study participants}

Table 2 shows knowledge on the treatment plan and regimen. Thirty-one $(8.9 \%)$ of the respondents knew the names of the ARV medications included in their regimen where as $91.1 \%$ of the patients did not know. From those who knew the names of the ARV regimen, all patients were taking the first line treatment regimens based on 2NRTIs + 1NNRTI (non/nucleoside reverse transcriptase inhibitor) where $45.2 \%$ of the patients were taking the combination of TDF $+3 \mathrm{TC}+$ EFV based regimen. Regarding knowledge on the treatment plan and regimen, $66.6 \%$ of patients were not knowledgeable and $33.4 \%$ of patients were found to be knowledgeable. From the total participants $(\mathrm{N}=350)$, the 2 NRTI +1 NNRTI based regimen was used by $93.3 \%$ of the study participants followed by NNRTI + PI (3.5\%) (Figure 1).

\section{Observance of the treatment by the study participants}

Two hundred and seventy-seven patients (79.1\%) reported $95 \%$ or more of the doses taken using self-report method. Using self-report, $40.9 \%$ had shown $100 \%$ adherence rate, $38.2 \%$ of patients of $95 \%$ to $99.9 \%$ adherence, and $20.9 \%$ showed adherence rate of $<95 \%$. On the other hand, 255 patients $(72.9 \%)$ reported $95 \%$ or more of the doses taken using pharmacy refill record method. Using pharmacy refill record, $16 \%$ had shown $100 \%$ adherence rate, $56.9 \%$
Table 1: Background characteristics of the study participants in TASH, 2013.

\begin{tabular}{|c|c|c|}
\hline Variables & $\mathrm{N}=350$ & Percentage \\
\hline \multicolumn{3}{|l|}{ 1. Sex } \\
\hline Male & 114 & 32.6 \\
\hline Female & 236 & 67.4 \\
\hline \multicolumn{3}{|l|}{ 2. Age } \\
\hline 19-30 & 75 & 21.4 \\
\hline $31-40$ & 140 & 40.0 \\
\hline $41-50$ & 89 & 25.4 \\
\hline+50 & 46 & 13.2 \\
\hline \multicolumn{3}{|l|}{ 3. Level of study } \\
\hline Uneducated & 39 & 11.1 \\
\hline Primary & 64 & 18.4 \\
\hline Secondary & 179 & 51.1 \\
\hline Tertiary & 68 & 19.4 \\
\hline \multicolumn{3}{|l|}{ 4. Employment } \\
\hline Unemployed & 203 & 58.0 \\
\hline Employed & 147 & 42.0 \\
\hline 5. Monthly income (USD) & $\mathrm{n}=160$ & \\
\hline$\leq 60$ & 135 & 84.4 \\
\hline $61-120$ & 9 & 5.6 \\
\hline $121-180$ & 9 & 5.6 \\
\hline $181-240$ & 3 & 1.8 \\
\hline $241-600$ & 2 & 1.3 \\
\hline$>601$ & 2 & 1.3 \\
\hline \multicolumn{3}{|l|}{ 6. ART start date } \\
\hline 1989-2000 & 38 & 10.9 \\
\hline $2001-2013$ & 312 & 89.1 \\
\hline \multicolumn{3}{|c|}{ 7. Alcohol consumption (per week) } \\
\hline None & 258 & 73.7 \\
\hline Once a week & 56 & 16.0 \\
\hline Twice a week & 17 & 4.9 \\
\hline Three times & 11 & 3.1 \\
\hline As often as I can & 8 & 2.3 \\
\hline
\end{tabular}

$\mathrm{N}$ : Total number of participants, n: number of patient from the total participants, USD: United States Dollar; conversion rate: 1USD=18.7 Birr

of patients of $95 \%$ to $99.9 \%$ adherence, and $27.1 \%$ showed adherence rate of $<95 \%$ (Table 3 ).

\section{Prevalence of factors for non-adherence to ART among the study participants}

As shown in Table 3, about $87.4 \%$ of respondents used memory aids to remember taking medications. From those who used memory aids, watch or alarm was being used by $70.6 \%$ of the participants. Among all the participants, $70.3 \%$ have at least had a substitution of regimen once where the major reasons of substitution reported were side-effects $(50.4 \%)$ and substitution to combination regimen (14.6\%). Two hundred and three (58\%) 
Table 2: Knowledge on the treatment plan and regimen of the study participants about their ART treatment in wTASH, 2013.

\begin{tabular}{|c|c|c|}
\hline Variables & $\mathbf{N}=\mathbf{3 5 0}$ & Percentage \\
\hline \multicolumn{3}{|c|}{$\begin{array}{l}\text { 1. Knowledge on knowing the } \\
\text { names of the ARV drugs }\end{array}$} \\
\hline Knowledgeable & 31 & 8.9 \\
\hline Not knowledgeable & 319 & 91.1 \\
\hline 2. Treatment regimen & $\mathrm{n}=31$ & \\
\hline $\mathrm{TDF}+3 \mathrm{TC}+\mathrm{EFV}$ & 14 & 45.2 \\
\hline $\mathrm{TDF}+3 \mathrm{TC}+\mathrm{NVP}$ & 11 & 35.6 \\
\hline $\mathrm{ZDV}+3 \mathrm{TC}+\mathrm{EFV}$ & 2 & 6.4 \\
\hline $\mathrm{ZDV}+3 \mathrm{TC}+\mathrm{NVP}$ & 2 & 6.4 \\
\hline $\mathrm{d} 4 \mathrm{t}+3 \mathrm{TC}+\mathrm{NVP}$ & 2 & 6.4 \\
\hline \multicolumn{3}{|l|}{$\begin{array}{l}\text { 3. Knowledge on major } \\
\text { function of ARV }\end{array}$} \\
\hline Knowledgeable & 122 & 34.9 \\
\hline Not knowledgeable & 228 & 65.1 \\
\hline \multicolumn{3}{|c|}{$\begin{array}{l}\text { 4. Knowledge on treatment } \\
\text { schedule }\end{array}$} \\
\hline Knowledgeable & 310 & 88.6 \\
\hline Not knowledgeable & 40 & 11.4 \\
\hline \multicolumn{3}{|l|}{$\begin{array}{l}\text { 5. Knowledge of alcohol } \\
\text { effect on adherence }\end{array}$} \\
\hline Yes & 245 & 70.0 \\
\hline No/IDK & 105 & 30.0 \\
\hline \multicolumn{3}{|c|}{$\begin{array}{l}\text { 6. Knowledge on consequence } \\
\text { of missing doses }\end{array}$} \\
\hline Knowledgeable & 31 & 8.9 \\
\hline Not knowledgeable & 319 & 91.1 \\
\hline
\end{tabular}

$\mathrm{N}$ : Total number of participants, $\mathrm{n}$ : Number of patient from the total participants, TDF: Tenofovir, 3TC: Lamivudine, EFV: Efavirenz, NVP: Nevirapine, ZDV: Zidovudine, d4t: Stavudine, IDK: I don't know

of the patients had reported that they were not satisfied with their treatment out of which181 (51.7\%) of them gave reason for their dissatisfaction. The sources for dissatisfaction were side-effects $(67.4 \%)$, pill burden $(23.2 \%)$ and inconvenience on the dosage form $(9.4 \%)$. About $36 \%$ of patients were taking co-medications along with the ARV medication.

\section{The variables affecting adherence rate}

The distribution of factors for non-adherence to ART is shown in Table 4. Among all the factors reported to affect adherence, medication side-effect $(58.7 \%)$, lack of social support $(57.3 \%)$, taking co-medications (37.6\%), stigma (35.5\%), and long-term treatment $(23.7 \%)$ were the common factors as reported by participants as shown in Figure 2.

The results of bivariate analysis are shown in Table 5 . The effect of sex, level of education, employment status, monthly income, date of ART start and alcohol consumption,
Table 3: Observance of the treatment by the study participants in TASH, 2013.

\begin{tabular}{|c|c|c|}
\hline Variables & $\mathbf{N}=\mathbf{3 5 0}$ & Percentage \\
\hline \multicolumn{3}{|l|}{ 1. Use of memory aid } \\
\hline Yes & 306 & 87.4 \\
\hline No & 44 & 12.6 \\
\hline 2. Type of memory aids & $\mathrm{n}=306$ & \\
\hline Watch/alarm & 216 & 70.6 \\
\hline Family/friends & 24 & 7.8 \\
\hline Move with daily dose & 19 & 6.2 \\
\hline Television/radio & 34 & 11.2 \\
\hline More than one type & 13 & 4.2 \\
\hline 3. Trouble in taking medication & $\mathrm{n}=331$ & \\
\hline Missing doses & 140 & 42.3 \\
\hline Missing time of intake & 168 & 50.7 \\
\hline Running out of medication & 19 & 5.7 \\
\hline Stock out & 4 & 1.3 \\
\hline \multicolumn{3}{|l|}{ 4. Adherence rate } \\
\hline \multicolumn{3}{|l|}{ Self-report } \\
\hline $100 \%$ & 143 & 40.9 \\
\hline $95-99.9 \%$ & 134 & 38.2 \\
\hline$<95 \%$ & 73 & 20.9 \\
\hline \multicolumn{3}{|l|}{ 5. Pharmacy refill record } \\
\hline $100 \%$ & 56 & 16 \\
\hline $95-99.9 \%$ & 199 & 56.9 \\
\hline$<95 \%$ & 95 & 27.1 \\
\hline \multicolumn{3}{|l|}{ 6. Treatment satisfaction } \\
\hline Yes & 147 & 42.0 \\
\hline No & 203 & 58.0 \\
\hline 7. Reasons for dissatisfaction & $\mathrm{n}=181$ & \\
\hline Pill burden & 42 & 23.2 \\
\hline Side effect & 122 & 67.4 \\
\hline Inconvenient on dosage form & 17 & 9.4 \\
\hline \multicolumn{3}{|l|}{ 8. Co-medication } \\
\hline Yes & 125 & 35.7 \\
\hline No & 225 & 64.3 \\
\hline
\end{tabular}

$\mathrm{N}$ : Total number of participants, $\mathrm{n}$ : Number of patient from the total participants

treatment regimen type, adherence counseling, social support and HIV stigma were not statistically significant against adherence rate. On the other hand, age (Crude odds ratio $[\mathrm{COR}][95 \% \mathrm{CI}]=0.60[0.37,0.97])$ using pharmacy refill record, knowledge on the treatment plan and regimen (COR $[95 \% \mathrm{CI}]=2.13[1.23,3.67])$ using pharmacy refill record, use of memory aid (COR $[95 \% \mathrm{CI}]=3.97[2.05,7.72])$ using self-report and (COR $[95 \% \mathrm{CI}]=2.56[1.34,4.91])$ using pharmacy refill record, treatment satisfaction (COR $[95 \% \mathrm{CI}]=2.42[1.37,4.33])$ using self-report and (COR $[95 \% \mathrm{CI}]=2.56[1.59,4.31])$, and taking co-medication $(\mathrm{COR}[95 \% \mathrm{CI}]=0.56[0.32,0.95])$ using self-report, regimen substitution $(\mathrm{COR}[95 \% \mathrm{CI}]=0.31[0.15,0.63])$ 


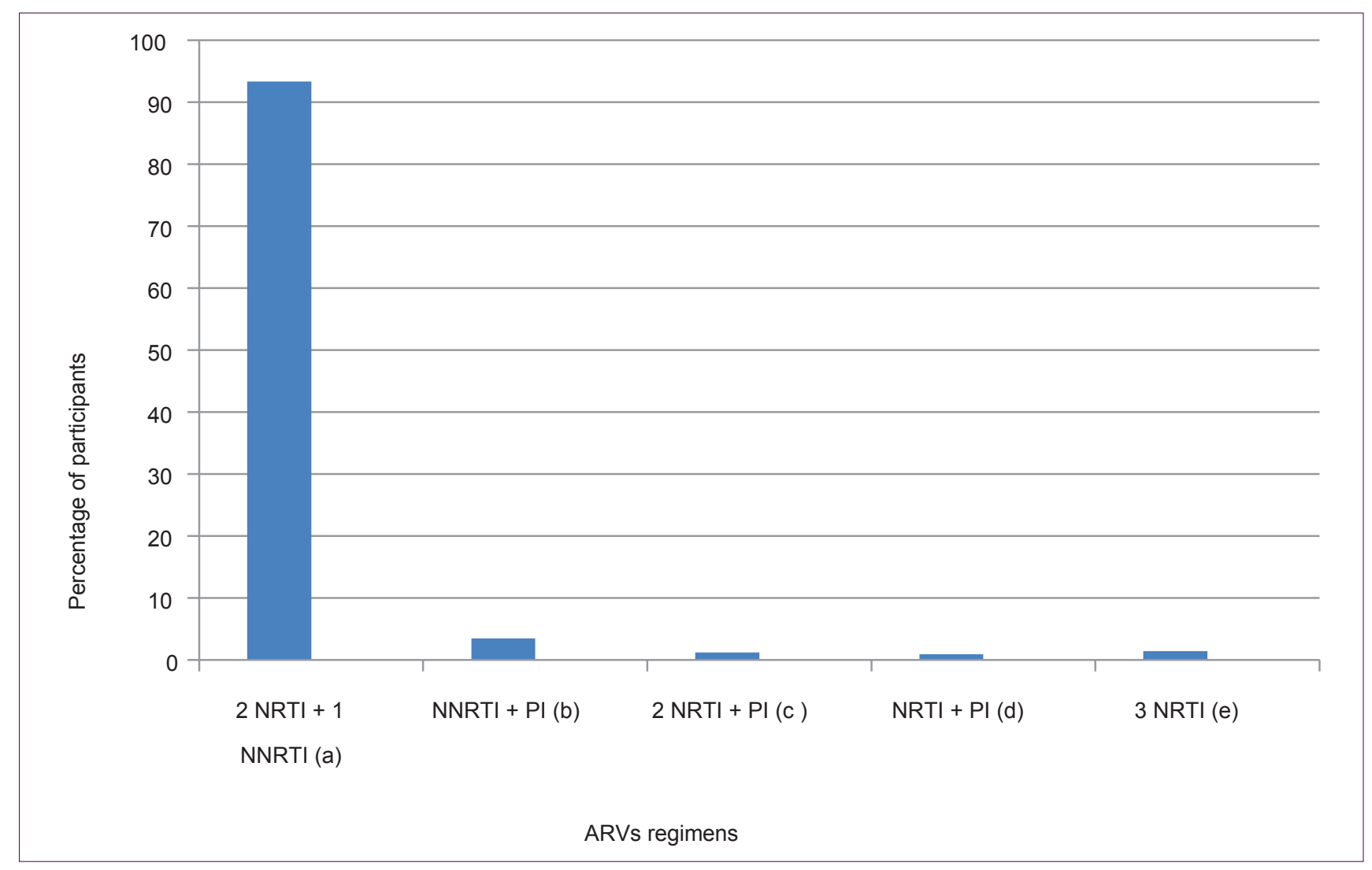

Figure 1: Distribution of patients according to ARV regimens prescribed. (a): TDF+3TC+EFV, TDF+3TC+NVP, ZDV+3TC+EFV, ZDV+3TC+NVP, ddi+3TC+NVP, ABC+3TC+EFV; (b): NVP+Lpv/r, EFV+Lpv/r;

(c): ZDV+3TC+Lpr/r; (d): ZDV+Lpv/r; (e): ABC+3TC+ZDV; TDF = Tenofovir; ZDV = Zidovudine; 3TC = Lamivudine; EFV = Efavirenz; ddi=Didanosine; $\mathrm{ABC}=$ Abacavir; $\mathbf{d 4 T}=$ Stavudine; $\mathrm{NVP}=$ Nevirapine; Lpr/r=Lopinavir boosted Ritonavir, $\mathbf{P I}=$ Protease inhibitor, $\mathrm{N}$ : Total number of participants.

using self-report and $(\mathrm{COR}[95 \% \mathrm{CI}]=0.45[0.25,0.81])$ using pharmacy refill record and medication side-effect (COR $[95 \% \mathrm{CI}]=0.54[0.34,0.89])$ using pharmacy refill record were found to be statistically associated with adherence rate.

In the multivariate analysis, the effect of medication sideeffect was not significantly associated with adherence rate. Age $($ AOR $[95 \% \mathrm{CI})=0.51[0.30,0.85])$ using pharmacy refill record, knowledge on the treatment plan and regimen $(\operatorname{AOR}(95 \% \mathrm{CI})=2.50[1.39,4.51])$, use of memory aid $(\mathrm{AOR}[95 \% \mathrm{CI}]=3.46[1.72,6.98])$ using self-report and $(\mathrm{AOR}[95 \% \mathrm{CI}]=2.71[1.34,5.47])$ using pharmacy refill record, treatment satisfaction $(\mathrm{AOR}[95 \% \mathrm{CI}]=2.23[1.22$, 4 s.07]) using self-report and (AOR [95\% CI] $=3.78[1.47$, 9.71]) using pharmacy refill record, taking co-medication $($ AOR $[95 \% \mathrm{CI}]=0.56[0.32,0.98])$, regimen substitution $(\mathrm{AOR}[95 \% \mathrm{CI}]=0.41[0.19,0.85])$ using self-report and (AOR $[95 \% \mathrm{CI}]=0.50[0.27,0.92])$ were found to be statistically associated with adherence rate (Table 6).

\section{Measurement of agreement between self-report and pharmacy refill record methods}

In measuring the agreement between self-report and pharmacy refill record methods, a kappa value of
0.735 was found. Two hundred and forty-nine and 67 participants were found to be adherent and non-adherent respectively in both methods. On the other hand, from those who claimed to be adherent using the self-report method, 28 participants were found to be non-adherent by pharmacy refill record method and from those who claimed to be non-adherent using self-report 6 participants were found to be adherent in using pharmacy refill record overall giving a total of agreement of 316 and giving a total disagreement of 34 .

\section{DISCUSSION}

The present study was carried out with the objectives to assess the extent of knowledge on the treatment plan and regimen, determine the rate of adherence to ART and identify factors related to non-adherence to ART at TASH. The adherence rate of the study participants was $79.1 \%$ using self-report and $72.9 \%$ using pharmacy refill records which are lower to the result found in the study conducted in some East African countries: Ethiopia, Kenya, Rwanda, and Uganda (96\%), ${ }^{16}$ in Senegal (91\%), ${ }^{17}$ and in Botswana (98\%). ${ }^{18}$ These results are also comparable with similar studies done in Ethiopia, $72.4 \%,{ }^{19} 81.2 \%,{ }^{20}$ and $82.8 \%{ }^{21}$ In other words, in this study $20.9 \%$ and $27.1 \%$ of patients 
Table 4: Factors of non-adherence by the study participants in TASH, 2013.

\begin{tabular}{|c|c|c|}
\hline Variables & $\mathbf{N}=\mathbf{3 5 0}$ & Percentage \\
\hline \multicolumn{3}{|l|}{ 1. Regimen switch } \\
\hline Yes & 246 & 70.3 \\
\hline No & 104 & 29.7 \\
\hline 2. Reason for regimen switch & $\mathrm{n}=246$ & \\
\hline Inefficiency of treatment & 15 & 6.1 \\
\hline Side effect & 124 & 50.4 \\
\hline Combination regimen & 36 & 14.6 \\
\hline Sickness & 13 & 5.3 \\
\hline Other & 14 & 5.7 \\
\hline I don’t know & 44 & 17.9 \\
\hline 3. Type of side effect* & $\mathrm{n}=195$ & \\
\hline Digestive related & 50 & 25.6 \\
\hline Lipoatrophy & 30 & 15.1 \\
\hline Skin related & 14 & 7.2 \\
\hline $\begin{array}{l}\text { Extremities of pain, } \\
\text { numbing, swelling }\end{array}$ & 30 & 15.8 \\
\hline Headache & 19 & 9.7 \\
\hline Buffalo hump & 20 & 10.3 \\
\hline Joint pain & 15 & 7.7 \\
\hline Other & 17 & 8.7 \\
\hline \multicolumn{3}{|l|}{ 4. Adherence counseling } \\
\hline Yes & 151 & 43.1 \\
\hline No & 199 & 56.9 \\
\hline \multicolumn{3}{|l|}{ 5. Social support } \\
\hline Yes & 160 & 45.7 \\
\hline No & 190 & 54.3 \\
\hline \multicolumn{3}{|l|}{ 6. Stigma } \\
\hline Agree & 93 & 26.6 \\
\hline Disagree & 182 & 52.0 \\
\hline I don't know & 75 & 21.4 \\
\hline
\end{tabular}

*Represent total more than total sample size $(\mathrm{N}=350)$. N: Total number of participants, $n$ : Number of patient from the total participants

have shown to have adherence rate $<95 \%$ using self-report and pharmacy refill record respectively. In comparison to studies in resource poor countries, the non-adherence rate was comparable to Kenya reported (18\%), ${ }^{22}$ the continental prevalence for Africa (23\%), ${ }^{23}$ Jimma University Specialized Hospital (21\%), ${ }^{5}$ and to Yirgalem Hospital (26.1\%). ${ }^{24}$ The slight inconsistency with these findings might be attributed to the differences in the study population and the adherence assessment methods employed. ${ }^{24}$

Some studies in resource rich settings have documented $<55 \%$ of patients taking all their ARV medications on time and according to medication instructions..$^{25,26}$ Bonolo et al. ${ }^{27}$ reviewed 43 articles on adherence to ART and they found a mean rate of non-adherence of $30.4 \%$, range from $5 \%$ to
$67 \%$. Comparing the current study to the mean non-adherence rate reported by the review, the review showed higher nonadherence rate confirming that patients in developed countries show poor adherence than developing countries. The possible explanation for the better adherence in this study might be due to most participants $(89.1 \%)$ started ART in recent years (2001-2013) when participants are experiencing dramatic increases in health status and before they develop long-term adverse effects of therapy as supported by a meta-analysis study by Mills et al. in North America and Africa ${ }^{23}$ or due to phenomenon of social capital. ${ }^{1}$

Several variables thought to affect adherence were assessed to examine for association with adherence rate. Age, knowledge on the treatment plan and regimen, use of memory aids, treatment satisfaction, taking co-medications and regimen substitution were the significant variables associated with adherence rate using both self-report and pharmacy refill record methods. The average age in this study (40 years) was greater than that reported in Senegal (38 years) ${ }^{28}$ Bothswana (35.6 years) ${ }^{18}$ and in United Kingdom (35.8). ${ }^{29}$ Age group $>40$ years of age was found to be more adherent than with age groups $<40$ years of age consistent with findings of other studies. $^{22,30}$ This can be explained by survivor effect in that, individuals who maintain greater compliance with treatment recommendations may actually outlive those who are non-adherent as explained by Wakibi et al. ${ }^{22}$

Socio-economic factors such as level of education, employment status and monthly income, did not significantly influence adherence in this study. Findings with respect to monthly income were consistent with the findings in South Africa. ${ }^{31}$ Finding on level of education was consistent with the findings in Botswana ${ }^{17}$ and finding in Nigeria $^{32}$ was similar with this study with respect to employment status. Similarly, date of ART started did not significantly influence adherence in this study inconsistent with finding in United Kingdom. ${ }^{29}$ In addition, consumption of alcohol was not found to be significantly associated with adherence inconsistent with other findings where alcohol was found to be a risk factor for non-adherence..$^{29,33}$

Assessment of treatment regimens indicated that the standard triple ARV regimens and two ARV based regimens were prescribed in the study. About 329 (94.7\%) of the total participants were prescribed 2 NRTIs +1 NNRTI-based regimens. This proportion of the regimen is much higher to that observed by Potchoo et al., (59.6\%) among the other regimens prescribed in the study. ${ }^{15}$ These regimens available in many sub-Saharan African countries are recommended because of their virological and immunological efficacy. ${ }^{17,28}$ The loose regimens for adults available in TASH: $\mathrm{d} 4 \mathrm{t}+3 \mathrm{TC}+\mathrm{NVP}$ and ZDV + $3 \mathrm{TC}+\mathrm{NVP}$, were only used by $59(6.3 \%)$ of participants which showed no statistical significant association between treated groups placed on these loose regimens and who were not. This can be due to smaller proportion 


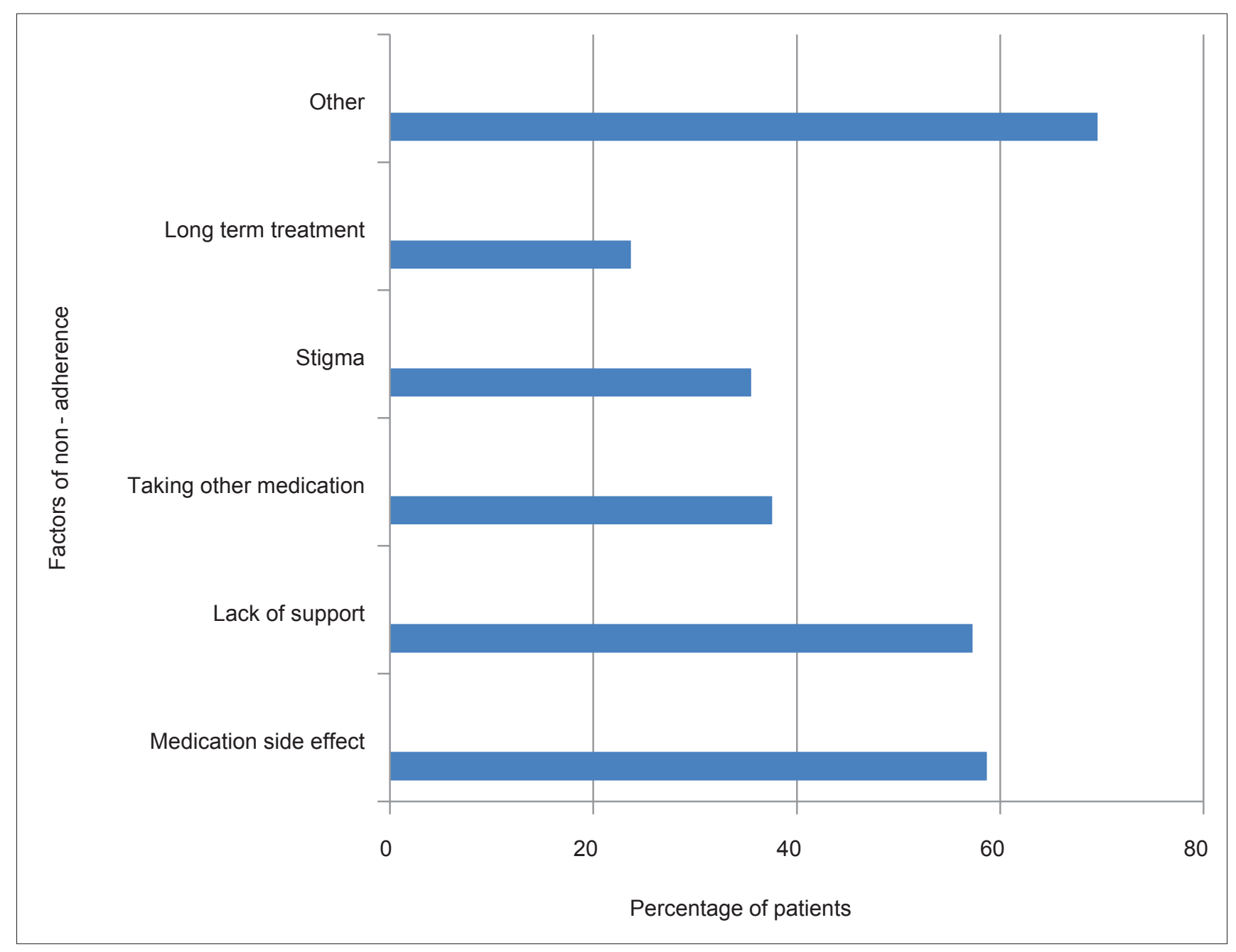

Figure 2: The most common factors of non-adherence reported by the study participant in TASH, 2013 (n=350). The sum of the percentages of all the factors of non-adherence is more than $100 \%$. The "others" refers to all the factors including forgetfulness, lack of interest, mobility, pill burden, poor health and sickness.

of patients on the loose regimens similar to study observed by Potchoo et al. ${ }^{15}$

Results on knowledge on the treatment plan and regimen showed that $33.4 \%$ of participants had good knowledge, whereas $66.6 \%$ had poor knowledge on the treatment plan and regimen. In this study, participants who had poor knowledge about the ARV drugs were found to be adhering lesser than the ones who had good knowledge. Knowledge that patients should have on treatment plan and the regimen, the cognitive requirements, side-effects and various demands around medication could be targeted as necessary components of adherence. ${ }^{5,13}$ Therefore, every patient needs to understand the importance of adherence because inaccurate information and misconceptions toward the disease and treatment regimens are associated with poor therapeutic outcomes that in turn may be an impediment to achieving optimal rate of adherence. ${ }^{29}$

The use of memory aids to remember medication intake was significantly associated with adherence. Participants who did not use memory aids were adhering lesser than those who used. Most patients (87.4\%) reported using memory aids where using watch/alarm $(61.7 \%)$ being the common memory aid used similarly shown by the study conducted by Potchoo et al. ${ }^{15}$ In light of this, patients have asked to be supported with hand watch, pill box and other memory aids so that they can improve their adherence.

Factors such as medication side-effect, lack of support $(20.2 \%)$, taking other medication, stigma and long term treatment have been cited as the main factors influencing the adherence which are also often reported in similar other studies. ${ }^{17}$ Most participants $(94.8 \%)$ chose two or more of the factors mentioned above for reason of non-adherence. Among the factors, ART medication side-effects was one of the mostly mentioned reason in the study affecting adherence which was collected on the basis of patients' reports. In this study however, medication side-effect was not significantly associated with non-adherence inconsistent with finding in Brazil $^{27}$ and other finding in Southern Ethiopia. ${ }^{24}$

Treatment dissatisfaction was significantly associated with non-adherence in this study. Participants who claimed to be 
Table 5: The relationship between background characteristics and ART adherence rate in TASH, 2013.

\begin{tabular}{|c|c|c|c|c|}
\hline \multirow[t]{2}{*}{ Variables } & \multirow[t]{2}{*}{ Methods } & \multicolumn{2}{|c|}{$\geq 95 \%$ ART adherence } & \multirow[t]{2}{*}{ COR $(95 \%)$} \\
\hline & & Yes N (\%) & No $\mathbf{N}(\%)$ & \\
\hline \multirow[t]{6}{*}{ Sex } & 1. Self-report & & & \\
\hline & Male & $90(78.9)$ & $24(21.1)$ & 1 \\
\hline & Female & $187(79.2)$ & $49(20.8)$ & $0.98(0.56,1.70)$ \\
\hline & 2. Pharmacy refi & & & \\
\hline & Male & $82(71.9)$ & $32(28.1)$ & 1 \\
\hline & Female & $173(73.7)$ & $63(26.7)$ & $0.93(0.56,1.54)$ \\
\hline \multirow[t]{6}{*}{ Age } & 1. Self-report & & & \\
\hline & $<40$ & $127(76.0)$ & $40(24)$ & 1 \\
\hline & $\geq 40$ & $150(82.0)$ & $33(18.0)$ & $0.69(0.42,1.17)$ \\
\hline & 2. Pharmacy refi & & & \\
\hline & $<40$ & $113(67.7)$ & $54(32.3)$ & 1 \\
\hline & $\geq 40$ & $142(77.6)$ & $41(22.4)$ & $0.60(0.37,0.97)^{*}$ \\
\hline \multirow[t]{6}{*}{ Level of study } & 1. Self-report & & & \\
\hline & Uneducated & $30(76.9)$ & $9(23.1)$ & 1 \\
\hline & Educated & $247(79.4)$ & $64(20.6)$ & $0.86(0.39,1.91)$ \\
\hline & 2. Pharmacy refi & & & \\
\hline & Uneducated & $30(76.9)$ & $9(23.1)$ & 1 \\
\hline & Educated & $225(72.3)$ & $86(27.7)$ & $1.27(0.58,2.79)$ \\
\hline \multirow[t]{6}{*}{ Employment } & 1. Self-report & & & \\
\hline & Unemployed & $121(82.3)$ & $26(17.7)$ & 1 \\
\hline & Employed & $156(76.8)$ & $47(27.2)$ & $0.71(0.41,1.22)$ \\
\hline & 2. Pharmacy refi & & & \\
\hline & Unemployed & $109(74.1)$ & $38(25.9)$ & 1 \\
\hline & Employed & $146(71.9)$ & $57(32.9)$ & $0.89(0.55,1.44)$ \\
\hline \multirow[t]{6}{*}{ Monthly income (USD) } & 1. Self-report & & & \\
\hline & $\leq 120$ & $122(84.7)$ & $22(15.3)$ & 1 \\
\hline & $>120$ & $12(75.0)$ & $4(25.0)$ & $1.84(0.54,6.25)$ \\
\hline & 2. Pharmacy refi & & & \\
\hline & $\leq 120$ & $112(77.8)$ & $32(22.2)$ & 1 \\
\hline & $>120$ & $10(62.5)$ & $6(37.5)$ & $2.10(0.71,6.22)$ \\
\hline \multirow[t]{6}{*}{ ART start date } & 1. Self-report & & & \\
\hline & $<5$ & $90(76.9)$ & $27(23.1)$ & 1 \\
\hline & $\geq 5$ & $187(80.3)$ & $46(19.7)$ & $0.82(0.47,1.40)$ \\
\hline & 2. Pharmacy refi & & & \\
\hline & $<5$ & $80(68.4)$ & $37(31.6)$ & 1 \\
\hline & $\geq 5$ & $175(75.1)$ & $58(24.9)$ & $0.72(0.44,1.17)$ \\
\hline \multirow[t]{6}{*}{ Alcohol consumption } & 1. Self-report & & & \\
\hline & No & $203(78.7)$ & $55(21.3)$ & 1 \\
\hline & Yes & $74(80.4)$ & $18(19.6)$ & $0.89(0.49,1.62)$ \\
\hline & 2. Pharmacy refi & & & \\
\hline & No & $187(72.5)$ & $71(27.5)$ & 1 \\
\hline & Yes & $68(73.9)$ & $24(26.1)$ & $0.93(0.54,1.59)$ \\
\hline
\end{tabular}

*Statistically significant in the univariate analysis. N: Total number of participants, COR: Crude odds ratio

dissatisfied were found to be adhering lesser than those who were satisfied. Out of 203 who claimed to be dissatisfied with the treatment, 181 participants disclosed their source of dissatisfaction whereas the remaining participants did not due to unwillingness to report their reasons of dissatisfaction. Treatment satisfaction can be a strong motivation tool for 
Table 6: The relationship between knowledge on the treatment plan and regimen and adherence rate in TASH, 2013.

\begin{tabular}{|c|c|c|c|c|}
\hline \multirow[t]{2}{*}{ Variables } & \multirow[t]{2}{*}{ Methods } & \multicolumn{2}{|c|}{$\geq 95 \%$ ART adherence } & \multirow[t]{2}{*}{ COR $(95 \%)$} \\
\hline & & Yes N (\%) & No N $(\%)$ & \\
\hline \multirow[t]{6}{*}{ Type of regimen } & 1. Self-report & & & \\
\hline & Fixed regimen & $48(81.4)$ & $11(18.6)$ & 1 \\
\hline & Not fixed regimen & $229(78.9)$ & $62(21.3)$ & $1.18(0.57,0.41)$ \\
\hline & 2. Pharmacy refill rep & & & \\
\hline & Fixed regimen & $44(74.6)$ & $15(25.4)$ & 1 \\
\hline & Not fixed regimen & $211(72.5)$ & $80(27.5)$ & $1.11(0.58,0.12)$ \\
\hline \multirow[t]{6}{*}{ Knowledge questions } & 1. Self-report & & & \\
\hline & Good & $94(80.3)$ & $23(19.7)$ & 1 \\
\hline & Poor & $183(78.5)$ & $50(21.5)$ & $1.12(0.64,1.94)$ \\
\hline & 2. Pharmacy refill rep & & & \\
\hline & Good & $96(82.1)$ & $21(17.8)$ & 1 \\
\hline & Poor & $159(68.2)$ & $74(31.8)$ & $2.13(1.23,3.67)^{*}$ \\
\hline
\end{tabular}

*Statistically significant in the univariate analysis. N: Total number of participants, COR: Crude odds ratio

adherence as reported by studies such as Markos et al. ${ }^{24}$ and Lyimo et al. ${ }^{33}$ Based on thematic analysis, some of these commonly reported source of dissatisfactions were consequences of ART side-effects (67.4\%) and pill burden $(23.2 \%)$ similar with finding by Bonolo et al. ${ }^{27}$ Taking comedication was found to be significantly associated with nonadherence. Participants who did not take co-medications were found to be adhering more than who were taking. Taking co-medications can be particularly difficult, especially for the uneducated population due to the difficulty to comply with the complex treatment regimen with the resultant forgetfulness leading to non-adherence. ${ }^{1}$ As reported by a study, pill burden from the ARV drugs is a factor for non-adherence ${ }^{34}$ which can increase the problem of non-adherence.

Regimen substitution has been found to be significantly associated with adherence. Participants who did not have ARV regimen substitution were shown to be adhering more than who did not. The major reasons for regimen substitution reported were side-effect $(50.4 \%)$ as reported by other studies as well. ${ }^{24,33}$ Regimen substitution requires adjustment in learning the new medication prescribed about the treatment dosing, time of intake and deal with many individual based inconveniences which might be challenging and reason for non-adherence. Adherence counseling, HIV stigma and social support were not found to be significantly associated with adherence in this study. Finding on adherence counseling was inconsistent with finding by Wasti et al. ${ }^{26}$ and El-Khatib et al. ${ }^{15}$ where adherence counseling and education interventions have been effective in improving adherence. HIV stigma is a common reason claimed for non-adherence by several studies such as Charurat et al. ${ }^{32}$ and Wakibi et al. ${ }^{35}$ but HIV stigma was not found to be statistically significant in this study inconsistent with these findings. Social support has been a constant predictor of non-adherence especially in resource limited countries in several studies. ${ }^{5,11,13}$ Contrary to these studies however, statistical association between social support and treatment adherence was not found in this study.
The most commonly reported side-effects were digestive system related problems, lipoatrophy, pain, numbing, and swelling of the extremities and buffalo hump similar to a study conducted at Yirgalem hospital. ${ }^{24}$ In this study, medication side-effect has been cited as factor for treatment dissatisfaction, reason of regimen substitution and reason for non-adherence. This implicate medication side-effects though not statistically significant in this study, should be given due emphasis from clinical, dispensing visit as well as during ongoing adherence counseling, and follow-up visit. Interventions aimed at solving medication side-effect, and thereby optimizing the benefit of effective therapies should be sought in detail by health care providers.

The assessment of adherence rate by interviewing HIV/ AIDS patients and reviewing pharmacy refill record seems to be an acceptable method in Africa. It is simple, cheap and accessible. Because taking medicine is a private affair, all adherence rate measurements are indirect. ${ }^{27}$ The "Substantial agreement" $(\mathrm{k}=0.735)$ between the two methods; self-report and pharmacy refill record was predictive of adherence which supports the validity of each of the measures. The adherence rate found using self-report measure was significantly correlated with pharmacy refill record and therefore, selfreport was reliably predictive of adherence in this study period similar with studies by Chee-Jen et al. ${ }^{10}$ In general, the findings of this study should be interpreted with some limitations. Because it was conducted at a single site, the findings may not be generalizable to other clinical settings. We were also unable to relate the obtained adherence rate to more accurate measures of adherence such as the viral load count and CD4 cell response due to logistical barriers to frequent laboratory monitoring in this setting. Thus, the rate of treatment adherence reported should be interpreted cautiously in light of the possibility of these limitations. Despite the aforementioned limitations, the study addressed several variables that can describe adherence with a high participation rate and could offer an opportunity for people 
living with HIV/AIDS to talk about living with HIV in a society where this is generally problematic.

\section{CONCLUSION}

The adherence rate found in this study is comparable to other resource limited settings and higher than developed countries. In this study, only $33.4 \%$ of the participants were found to have good knowledge on the treatment plan and regimen, $79.1 \%$ and $72.9 \%$ of the participant showed an adherence rate of $\geq 95 \%$ and participants who used memory aids, who were satisfied with their treatment, who are not taking co-medications and never had regimen switch were found to be more adherent to ART treatment than to the corresponding comparison groups using both the self-report and pharmacy refill record methods.

\section{ACKNOWLEDGMENTS}

The authors would like to acknowledge Office of Vice President for Research and Technology Transfer of Addis Ababa University for financial support.

\section{Funding: Addis Ababa University} Conflict of interest: None declared

Ethical approval: Was obtained from all participating institutions

\section{REFERENCES}

1. Monjok E, Smesny A, Okokon BI, Mgbere O, Essien JE. Adherence to antiretroviral therapy in Nigeria: an overview of research studies and implications for policy and practice. HIV/AIDS - Res Palliat Care. 2010;2:69-76.

2. World Health Organization (WHO). Antiretroviral therapy. 2011. Available from: http://www.who.int/hiv/topics/ treatment/art/en/index.html. [Last accessed on 2013 Mar 03].

3. World Health Organization (WHO). The strategic use of antiretroviral to help end the HIV epidemic. 2012. Available from: http://www.who.int. [Last accessed on 2013 Mar 03].

4. Amberbir A, Woldemichael K, Getachew S, Girma B, Deribe K. Predictors of adherence to antiretroviral therapy among HIV-infected persons: a prospective study in Southwest Ethiopia. BMC Cent Public Health. 2008;8:265.

5. Lazo M, Gange SJ, Wilson TE, Anastos K, Ostrow DG, Witt MD, et al. Patterns and predictors of changes in adherence to highly active antiretroviral therapy: longitudinal study of men and women. Clin Infect Dis. 2007;45:1377-85.

6. Murphy DA, Marelich WD, Rappaport NB, Hoffman D, Farthing C. Results of an antiretroviral adherence intervention: STAR (staying healthy: taking antiretrovirals regularly). J Int Assoc Physicians AIDS Care. 2007;6(2):113-24.

7. Li L, Lee SJ, Wen Y, Lin C, Wan D, Jiraphongsa C. Antiretroviral therapy adherence among patients living with HIV/AIDS in Thailand. Nurs Health Sci. 2010;12(2):212-20.

8. Gulick RM. Adherence to antiretroviral therapy: how much is enough? Clin Infect Dis. 2006;43:942-4.

9. Unge C, So dergard B, Marrone G, Thorson A, Lukhwaro A, Carter J, et al. Long-term adherence to antiretroviral treatment and program drop-out in a high-risk urban setting in Sub-saharan
Africa: a prospective cohort study. PLoS ONE. 2010;5:10.

10. Chee-Jen C, Ross-Degnan D, Pierre-Jacques M, Zhang F, Tadeg H, Gitau L, et al. Measuring adherence to antiretroviral treatment in resource-poor settings: the clinical validity of key indicators. BMC Health Serv Res. 2010;10:42.

11. Jones DL, Baker Shvawn Mc P, Lydston D, Camille J, Brondolo E, Tobin JN, et al. Efficacy of a group medication adherence intervention among HIV positive women: the SMART/EST women's project. Natl Inst Health: AIDS Behav. 2007;11(1):79-86.

12. Scanlon ML, Vreeman RC. Current strategies for improving access and adherence to antiretroviral therapies in resourcelimited settings. HIV/AIDS - Res Palliat Care. 2013;5:1-17.

13. Mills EJ, Nachega JB, Buchan I, Orbinski J, Attaran A, Singh S, et al. Adherence to antiretroviral therapy in Sub-Saharan Africa and North America. J Am Med Assoc. 2006;296:679-90.

14. Mengesha A, Worku A. Assessment of antiretroviral treatment among HIV infected persons in the Ministry of Defense Hospitals. AAU, MPH Thesis; 2005.

15. Potchoo Y, Tchamdja K, Balogou A, Pitche VP, Guissou IP, Kassang EK. Knowledge and adherence to antiretroviral therapy among adult people living with HIV/AIDS treated in the health care centers of the association "Espoir Vie Togo" in Togo, West Africa. Journal o BMCl Pharmacology 2010, 10:11.

16. Reda AA, Biadgilign S. Determinants of adherence to antiretroviral therapy among HIV-infected patients in Africa. AIDS Res Treat. 2012;2012:574656.

17. Weiser S, Wolfe W, Bangsberg D, Thior I, Gilbert P, Makhema J, et al. Barriers to antiretroviral adherence for patients living with HIV infection and AIDS in Botswana. J Acquir Immune Defic Syndr. 2003;34:281-8.

18. Lyimo RA, Bruin M, Boogaard J, Hospers HJ, Ven A, Mushi D. Determinants of antiretroviral therapy adherence in northern Tanzania: a comprehensive picture from the patient perspective. BMC Cent Public Health. 2012;12:716.

19. Potchoo Y, Tchamdja K, Balogou A, Pitche VP, Guissou IP, Kassang EK. Knowledge and adherence to antiretroviral therapy among adult people living with HIV/AIDS treated in the health care centers of the association "Espoir Vie Togo" in Togo, West Africa. BMC Clin Pharmacol. 2010;10:11.

20. FMOH. Health and Health Related Indicators, Planning and programming Department. Addis Ababa: FMOH; 2007.

21. Drug and Therapeutics Committee of Tikur Anbessa General Specialized Hospital in collaboration with PFSA and MSH/ SIAPS. List of pharmaceuticals for Tikur Anbessa specialized hospital. $1^{\text {st }}$ Edition. 2012. Addis Ababa, Ethiopia.

22. Ekama SO, Herbertson EC, Addeh EJ, Okafor CVG, Onwujekwe DI, Tayo F, et al. Pattern and determinants of antiretroviral drug adherence among Nigerian pregnant women. J Pregnancy. 2012;2012:851810.

23. Li L, Lee SJ, Thammawijayab P, Jiraphongsab C, Jane M, Borusa R. Stigma, social support, and depression among people living with HIV in Thailand. Natl Inst Health-AIDS Care. 2009;21(8);1007-13.

24. Markos E, Worku A, Davey G: Adherence to ART in PLWHA at Yirgalem Hospital, South Ethiopia. Ethiopian Journal of Health Development 2008;22(2):174-179.

25. Chalker JC, Andualem T, Gitau LN, Ntaganira J, Obua C, Tadeg, Hetal. Measuring adherence to antiretroviral treatment in resource-poor settings: the feasibility of collecting routine data for key indicators. BMC Health Serv Res. 2010;10:43.

26. Wasti SP, Simkhada P, Randall J, Freeman JV, van Teijlingen E. Factors influencing adherence to antiretroviral treatment in Nepal: a mixed-methods study. PLoS ONE. 2012;7:5. 
27. Bonolo PF, César CC, Acurcio FA, et al: Non-adherence among patients initiating antiretroviral therapy: a challenge for health professionals in Brazil. AIDS 2005;19(suppl 4):s5-s13.

28. Etard JF, Lanièce I, Fall MB, Cilote V, Blazejewski L, Diop K, Desclaux A, Ecochard R, Ndoye I, Delaporte E. A 84-month follow up of adherence to HAART in a cohort of adult Senegalese patients. Trop Med Int Health. 2007;12(10):1191-8.

29. Laniece I, Desclaux A, Ciss M, Diop K, Ndiaye B. Adherence to HAART and its principal determinants in a cohort of Senegalese adults. In: Desclaux A, Laniece I, Ndoye I, editors. Paris: ANRS; 2002: 97-108.

30. Kleebergera CA, Buechnera J, PalellabFra, Detelsc R, Riddlerd S, Godfreya R, et al. Changes in adherence to highly active antiretroviral therapy medications in the multicenter AIDS Cohort Study. AIDS. 2004;18:683-8.

31. Orrell C, Bangsberg DR, Badri M, Wood R. Adherence is not a barrier to successful antiretroviral therapy in South Africa. J Acquir Immune Defic Syndr. 2003;17:1369-75.

32. Charurat M, Oyegunle M, Benjamin R, Habib A, Eze E, Ele P, et al. Patient retention and adherence to antiretrovirals in a large antiretroviral therapy program in Nigeria: a longitudinal analysis for risk factors. PLoS ONE. 2010;5(5):e10584.

33. Lyimo RA, Bruin M, Boogaard J, Hospers HJ, Ven A, Mushi D. Determinants of antiretroviral therapy adherence in northern Tanzania: a comprehensive picture from the patient perspective. J Bio Med Cent Public Health. 2012;12:716.

34. American Public Health Association, 2004. Adherence to HIV treatment regimens: recommendations for best practices. Available from: http://www.apha.org/ppp/hiv.

35. Wakibi SN, W Ng'ang'a Z, Mbugua GG. Factors associated with non-adherence to highly active antiretroviral therapy in Nairobi, Kenya. AIDS Res Ther. 2011;8:43.

doi: $10.5455 / 2319-2003 . i j b c p 20140413$

Cite this article as: Demessie R, Mekonnen A, Amogne W, Shibeshi W. Knowledge and adherence to antiretroviral therapy among adult people living with HIV/AIDS at Tikur Anbessa Specialized Hospital, Ethiopia. Int J Basic Clin Pharmacol 2014;3:320-30. 